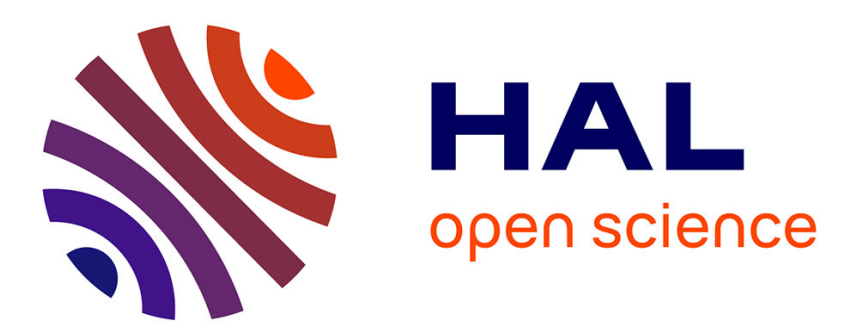

\title{
Steady state creep behavior of two ceramic composites SiCf-SiC and SiCf -MLAS
}

D. Kervadec, F. Abbe, J.-L. Chermant

\section{To cite this version:}

D. Kervadec, F. Abbe, J.-L. Chermant. Steady state creep behavior of two ceramic composites SiCf-SiC and SiCf -MLAS. Journal de Physique IV Proceedings, 1993, 03 (C7), pp.C7-1917-C7-1922. 10.1051/jp4:19937306 . jpa-00251950

\section{HAL Id: jpa-00251950 https://hal.science/jpa-00251950}

Submitted on 1 Jan 1993

HAL is a multi-disciplinary open access archive for the deposit and dissemination of scientific research documents, whether they are published or not. The documents may come from teaching and research institutions in France or abroad, or from public or private research centers.
L'archive ouverte pluridisciplinaire HAL, est destinée au dépôt et à la diffusion de documents scientifiques de niveau recherche, publiés ou non, émanant des établissements d'enseignement et de recherche français ou étrangers, des laboratoires publics ou privés. 


\title{
Steady state creep behavior of two ceramic composites $\mathrm{SiC}_{\mathrm{f}}-\mathrm{SiC}$ and $\mathrm{SiC}_{\mathbf{f}}-\mathrm{MLAS}$
}

\author{
D. KERVADEC, F. ABBE and J.-L. CHERMANT
}

LERMAT, URA 1317 du CNRS, ISMRA, 6 Bd du Maréchal Juin, 14050 Caen cedex, France

\begin{abstract}
Creep were performed by three-point bending under vacuum on $\mathrm{SiC}_{f}-\mathrm{SiC}$ and $\mathrm{SiC}_{\mathbf{f}}$-MLAS composites. The results are compared and discussed according to criteria based on the values of both temperature and stress and on the damaging features observed.
\end{abstract}

\section{INTRODUCTION}

Among the new materials under development for structural applications at high temperatures, ceramic matrix reinforced with continuous ceramic fibers - i.e. ceramic matrix composites, CMC - offer probably the greatest potential in the field of temperatures greater than 1300K. Despite their interest, very few investigations concern their creep behavior [1]. Into the French program developed on these CMC [2], where $\mathrm{SiC}_{f}-\mathrm{SiC}$ and $\mathrm{SiC}_{f}$-MLAS are the materials mainly investigated, creep tests are performed in our laboratory in correlation with their morphology and microstructure.

Among the main creep results performed by Abbé [3] on 2D $\mathrm{SiC}_{f}-\mathrm{SiC}_{\text {and }}$ by Kervadec [4] on 1D SiC -MLAS, in this paper we will briefly present some of their creep results on the steady state. The investigations performed by creep on different types of CMC have to inform on the creep damaging and on the effect of the creep of the different components, with and without an aging effect.
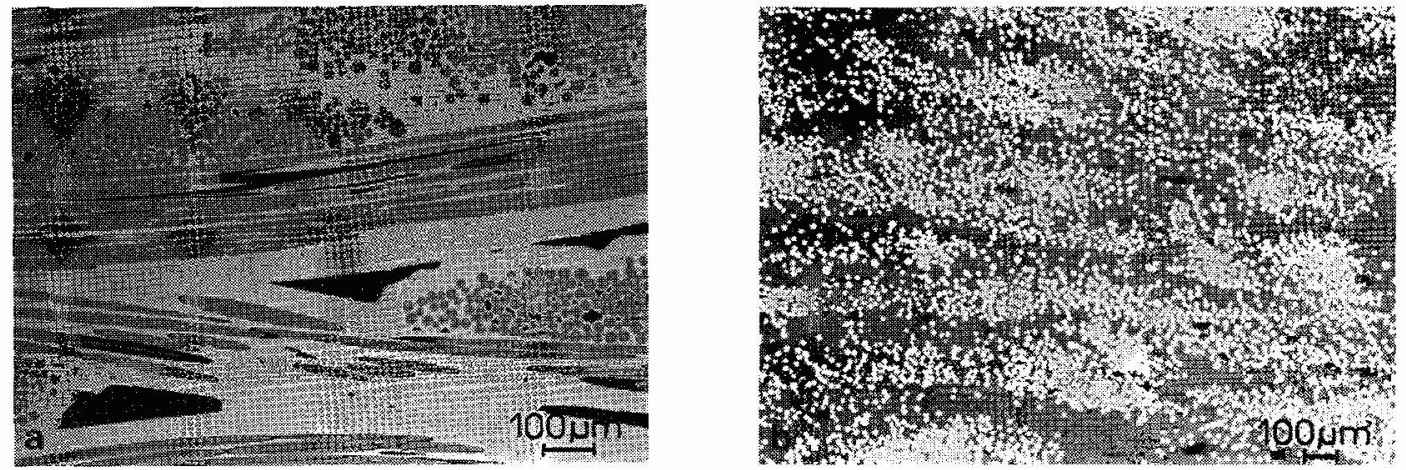

Fig. 1 : Optical micrographs of $\mathrm{SiC}_{f}-\mathrm{SiC}(\mathrm{a})$ and $\mathrm{SiC}_{f}-\mathrm{MLAS}$ (b) composites. 


\section{EXPERIMENTAL DETAILS}

The two CMC investigated differ on one way from the matrix and on the other way from their process route, but the same reinforcement is used, the Nicalon ${ }^{\mathrm{R}}$ NM 202 SiC fiber (Nippon Carbon, Japan).

The 2D SiC - SiC composites were elaborated by SEP (Etablissement de Bordeaux, France). A bidirectional cloth of $\mathrm{SiC}$ fibers with a carbon coating was infiltrated by a chemical vapor of $\mathrm{SiC}$ (CVI process), [5]. The matrix is then made of $\beta$ SiC columnar crystals, (Fig. 1a). The main morphological characteristics are given in Table I.

Table I : Morphological characteristics of the two CMC investigated, with $V_{v}(m), V_{v}(f)$ and $V_{v}(P)$, respectively the volumic fraction of matrix, fibers and pores.

\begin{tabular}{|c|c|c|c|}
\hline Material & $\mathrm{V}_{\mathrm{v}}(\mathrm{m})$ & $\mathrm{v}_{\mathrm{v}}(\mathrm{f})$ & $\mathrm{V}_{\mathrm{v}}(\mathrm{P})$ \\
\hline $\mathrm{SiC}_{\mathrm{f}}-\mathrm{SiC}$ & 45 to 50 & 40 & 15 to 10 \\
$\mathrm{SiC}_{\mathrm{r}}-$ MLAS & 67 & 32 & 1 \\
\hline
\end{tabular}

The 1D SiC -MLAS composites were elaborated by Aérospatiale (Etablissement d'Aquitaine, France). The aligned un-coated fibers were infiltrated by a slurry and then hot-pressed to obtain the vitroceramic matrix [6], (Fig. 1b). The composition of the slurry obtained from a sol-gel process is $0.5 \mathrm{MgO}-0.5 \mathrm{Li} \mathrm{O}_{2}-1 \mathrm{Al}_{2} \mathrm{O}_{3}-4 \mathrm{SiO}_{2}$. The final matrix is then a magnesium lithium aluminosilicate, with $\beta$ spodumene, $\alpha$ cordierite and a glassy phase. The morphological characteristics are given in Table I.

These composites differ not only from the matrix components, but also from their elastic moduli :

$$
\begin{array}{ll}
E_{f}<E_{m} & \text { for } \operatorname{SiC}_{f}-\operatorname{SiC} \\
E_{f}>E_{m} & \text { for } \operatorname{SiC}_{f}-\text { MLAS }
\end{array}
$$

All the creep tests were performed in three-point bending under vacuum with an INSTRON 1380 creep machine equiped with an opening furnace (Sésame, VMDI, France). Deformation was measured via 6 LVDT on the external parts of the furnace.

To compare their performances, we have considered only the temperature domain, $T$, where these CMC present similar strain rates, the applied stress domain, $\sigma$, being linked to the strength of the material at a given temperature. The following conditions have been used :

\begin{tabular}{|c|c|c|}
\hline $\operatorname{SiC}_{f}-\operatorname{SiC}$ & $1373-1673 \mathrm{~K}$ & $25-250 \mathrm{MPa}$ \\
\hline SiC $_{f}$ MLAS & $1173-1473 \mathrm{~K}$ & $25-400 \mathrm{MPa}$ \\
\hline
\end{tabular}

\section{RESULTS}

The experimental creep curves, $\varepsilon-t$, show always the three stages : primary or transitory, secondary or stationary, and tertiary leading to the rupture of the composite. Although the existence of a very well established stationary stage $\left(\dot{\varepsilon}_{s}=C t\right)$ is often discussed for ceramics and CMC [7], we observed such a stage which has been 

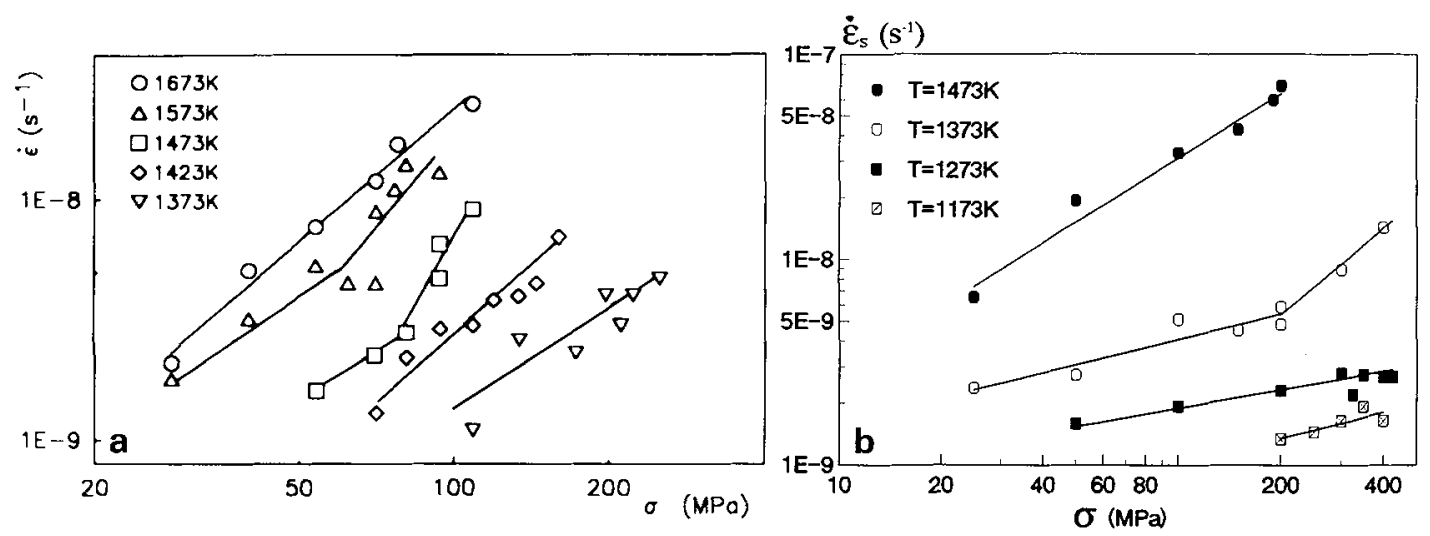

Fig. 2 : Creep rate in the stationary stage, $\dot{\varepsilon}_{s}$, as a function of the applied stress, $\sigma$, for $2 \mathrm{D} \mathrm{SiC}-\mathrm{SiC}(a)$ and $1 \mathrm{D} \mathrm{SiC}$-MLAS (b).

analyzed up to now from the classical Dorn formalism $\left(\dot{\varepsilon}_{\mathrm{s}}=\mathrm{A} \sigma^{\mathrm{n}}\right.$, A being a constant and $\mathrm{n}$ the stress, $\sigma$, exponent).

In figure 2 are presented the creep rate, $\dot{\varepsilon}_{s}$, as a function of the applied stress, $\sigma$, for these two CMC. In the frame of the Dorn formalism, the slope of the straight lines corresponds to the stress exponent $\mathrm{n}$, which characterizes the mechanism responsible for the strain. To compare the results of these two composites, we propose to use temperature, $T$, and stress, $\sigma$, criteria defined as following (Table II) :

- low and high temperature,

- low and high stress.

Table II : Values of the stress exponent, $n$, according to the different domains of temperature, $T$, and stress, $\sigma$, for the two CMC investigated.

\begin{tabular}{|c|c|c|}
\hline Creep conditions & $\mathrm{SiC}_{f}-\mathrm{SiC}$ & $\mathrm{SiC}_{f}$-MLAS \\
\hline low $\mathrm{T}$, low $\sigma$ & 1.4 & $0.3-0.4$ \\
low $\mathrm{T}$, high $\sigma$ & $3.2-5.6$ & 1.4 \\
high $\mathrm{T}$ & 1.7 & 1 \\
\hline
\end{tabular}

The morphological observations of the damaging of the $\mathrm{SiC}_{\mathrm{f}}$-MLAS specimens, for example crept at $1373 \mathrm{~K}$, evidence two main features :

- for the low T-low $\sigma$ domain (25-200 MPa), there appears microcracks parallel to the fibers, specially in the tensile zone of the specimen (Fig. 3a); these microcracks are probably the consequence and the second step of the interfacial matrix/fiber decohesion,

- for the low T-high $\sigma$ domain (200-400 MPa), we are over the yield stress of the composite, and there is matrix rupture and by consequence apparition of microcracks perpendicular to the fibers (Fig. $3 b$ ); this involves a decrease in the efficacious section of the specimen and then an acceleration of the strain [8].

Moreover we observed in the temperature range investigated that the fiber pull-out increases when the creep temperature is increased.

In the case of SiC-SiC specimens, microcracks are also observed. Generally they are stopped by the fibers at low temperatures 1373-1473K (Fig. 4a), while they round the fibers at higher temperatures (Fig.4b). Moreover contrarily to the SiC-MLAS composite behavior, the fiber pull-out decreases when the creep temperature is 

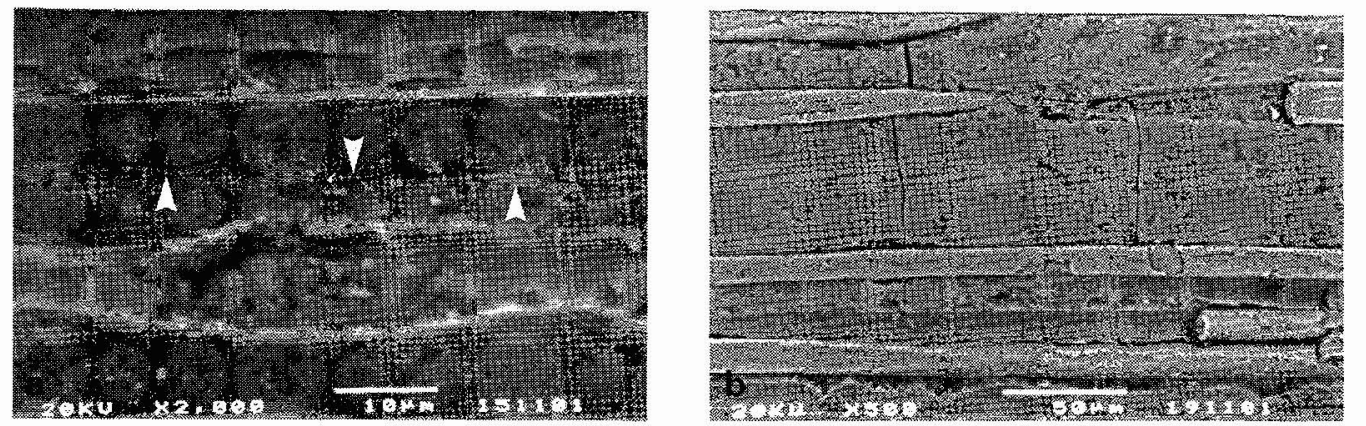

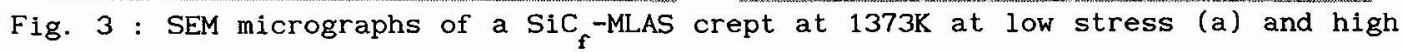
stress (b).

increased. These differences are due to the difference in the thermal expansion coefficients and Young moduli of the different components and on the fact that $\mathrm{SiC}_{\mathrm{f}}-\mathrm{SiC}$ composites have a carbon interface.
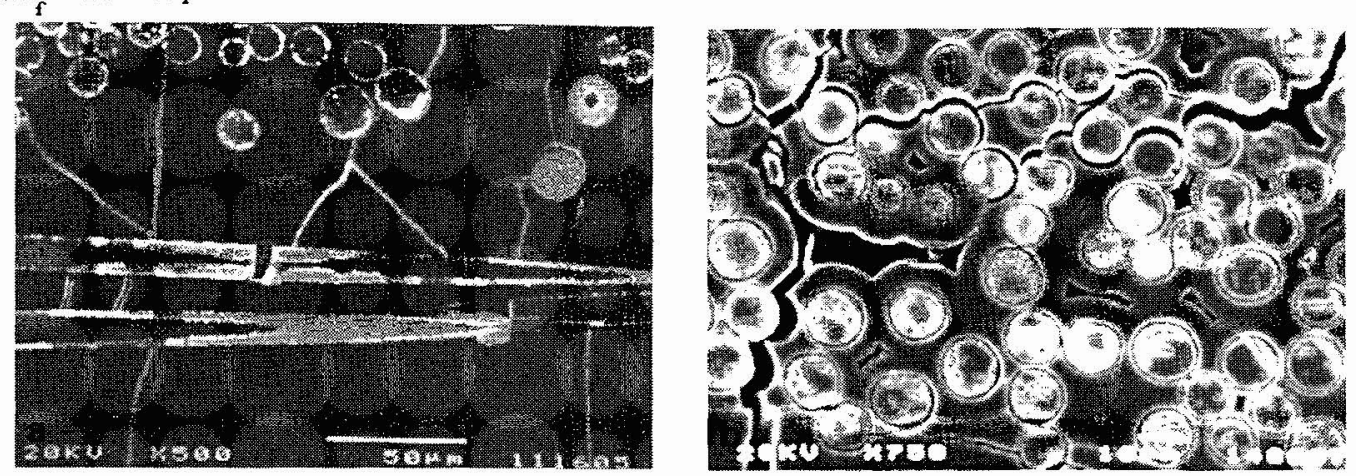

Fig. 4 : SEM micrographs of a SiC $-\mathrm{SiC}$ crept at $1373 \mathrm{~K}(\mathrm{a})$ and $1673 \mathrm{~K}(\mathrm{~b})$.

\section{DISCUSSION}

The first step of the mechanism governing the creep deformation in the steady stage of these composites will be discussed first on the basis of the damaging type appearing for $\mathrm{SiC}_{\mathrm{f}}$-MLAS and then extended to $\mathrm{SiC}_{\mathrm{f}}-\mathrm{SiC}$ composites.

The most surprising point presented previously is the low value of the stress exponent measured in the low $T$-low $\sigma$ domain : $n \cong 0.3-0.4$. Any mechanisms proposed up to now can explain these $n$ values. It must be based on the particularities of that ceramic composite with continuous fibers, with the coexistence of two phases of different characteristics and on the presence of specific interfaces.

At time $t=0$, these two phases are in the same stress state. During creep test, fibers and matrix are deformed in the stationary stage at creep rates respectively $\dot{\varepsilon}_{s}(\mathrm{f})$ and $\dot{\varepsilon}_{s}(\mathrm{~m})$ with : $\dot{\varepsilon}_{\mathrm{s}}(\mathrm{m})>\dot{\varepsilon}_{\mathrm{s}}(\mathrm{f})$ for $\mathrm{SiC}_{\mathrm{f}}$ MLAS at a given $\sigma$ and $\mathrm{T}$.

In the composite, this difference in the deformation puts the fiber/matrix cohesion to the test by shear stresses. At that time the degree of cohesion turns out to be essential : if the shear stresses are sufficiently important, then there is rupture of the fiber/matrix bonding. One must introduce the notion of threshold stress, $\sigma$,

below which the resulting shear stress will be not enough important to break the fiber/matrix bonding. In that case the stationary stage is governed by the strain of the fiber (the most strengthened component). If the creep strain of the $f$ iber is null, there is then saturation of the deformation after the transitory stage. 
If one looks for a stress greater than the threshold stress, an interfacial decohesion which propagates along the fibers during the creep test arises. One obtains therefore a regular deformation of the composite which could be stationary. The creep rate is then linked to the number of decohesions created in the specimens, so to the stress state in the specimen. In fact decohesion can arise only in the part of the specimen subjected to a stress greater than the threshold stress previously defined. This corresponds to the damaged zone, where the stress is greater than $\sigma$. The damaged zone has been calculated as a function of the applied stress, $\sigma_{a}$ in the case of specimens considered in a first step with a linear and pure elastic behavior. We have then plotted the isostress curves in the specimens ( $F i g$. 5a) and the change in the surface area of the damaged zone, $A$, as a function of the $\sigma / \sigma$. ratio (Fig. $5 b$ ).

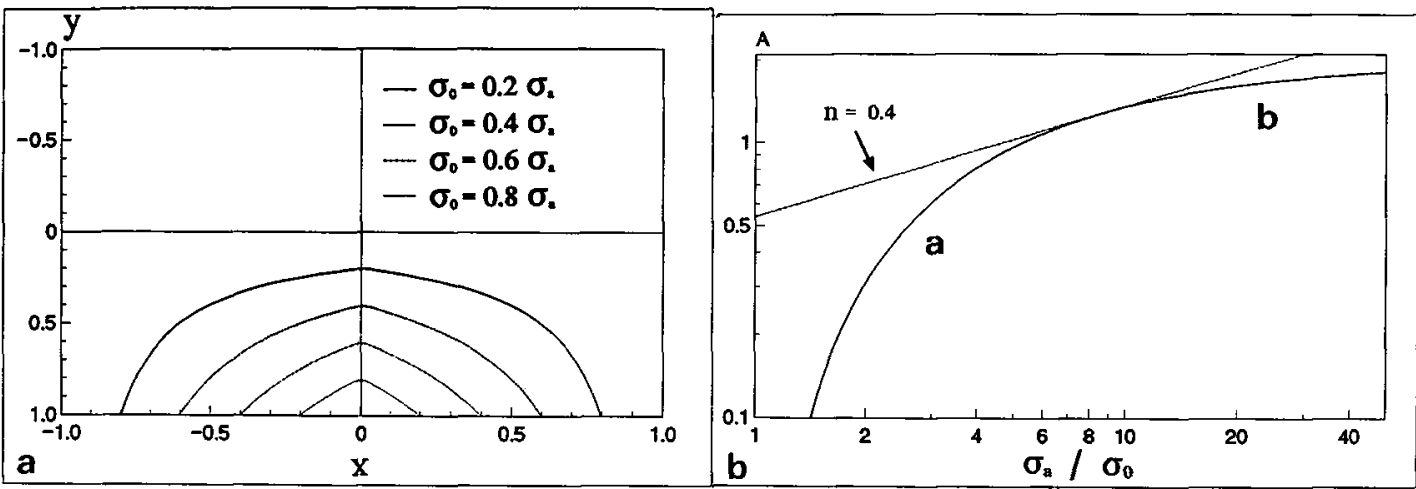

Fig. 5 : Distribution, of the stresses in the test specimen (a) and change in the surface area of the damaged zone, $A$, as a function of $\sigma_{a} / \sigma_{0}$ ratio and with the tangent corresponding to $n=0.4$, for SiC-MLAS, (b).

If we make the assumption that the creep rate $\dot{\varepsilon}_{s}$ is linked to the surface area of the damaging zone $A$, for a given stress, it could be possible to compare the obtained curves to the $\dot{\varepsilon}-\sigma$ experimental curves (in the case where $\mathrm{n}=0.4$ ). To the low values of A correspond very low creep rates un-accessible experimentally : that explains the lack of this section of curve (on the $\dot{\varepsilon}-\sigma$ plots). A visco-elastic approach would probably allow, in a second step, an extension of this domain of agreement of this $\dot{\varepsilon}-\sigma$ curve and the corresponding tangent for $\mathrm{n}=0.4$. Such a model is only valid for a stress lower or equal to the yield stress. For greater values it is necessary to take into consideration the reduction of the efficacious section due to the matrix microcracking [8].

SiC-MLAS and SiC-SiC composites have a temperature domain of applications which is different : a maximum of 1273K for SiC-MLAS and higher than 1473K for SiC-SiC. Moreover the first one is unidirectional and the second one bidirectional. So we can only compare the mechanisms arising in the low $\mathrm{T}$-low $\sigma$ domain where $n=0.3-$ 0.4 for SiC-MLAS and 1.4 for SiC-SiC.

To obtain equivalent creep rates, the stresses are lower for SiC-SiC than for SiCMLAS (but we are at higher temperature). This can be due (i) to the directional effect and (ii) to the fact that the Nicalon fiber being the same, the fiber deformation for SiC-SiC will be greater as the creep tests are performed at higher temperatures. Moreover the interfacial cohesion is stronger for SiC-SiC than for SiCMLAS where matrix viscous flow arises at low temperatures. This leads to the fact that for SiC-SiC the threshold stress is higher than for SiC-MLAS. Due to these two points, if we plot with the same hypothesis the curve $A=f\left(\sigma_{a} / \sigma_{0}\right)$, we have now access to part a of figure 5b. Moreover the yield stress for SiC-SiC is lower than for SiC-MLAS: that means that part $b$ of that curve will be truncated as there is a decreasing of the efficacious section. 


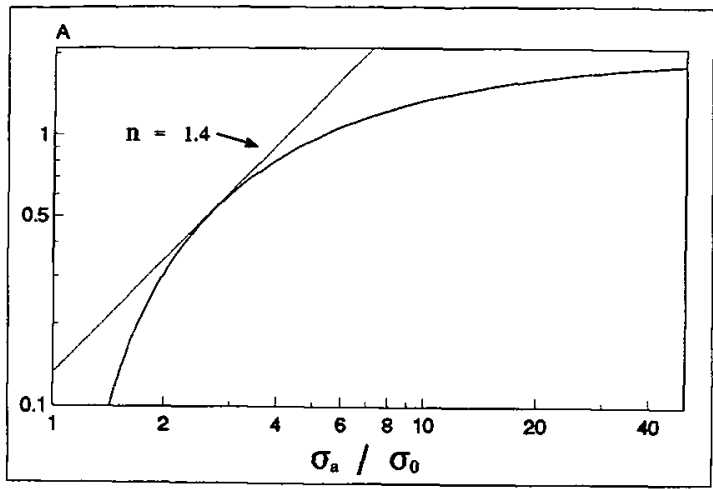

Fig. 6 : Change in the surface area of the damaged zone, A, as a function of $\sigma_{a} / \sigma$ 。 ratio and with a tangent corresponding to $\mathrm{n}=1.4$, for $\mathrm{SiC}_{\mathrm{f}}-\mathrm{SiC}$.

The appearance of the curve on figure 6, corresponding to SiC-SiC can explain that the $n$ value is greater than for SiC-MLAS and the fact that a slope of 1.4 can correspond to the same mechanism for the first step : damaging by decohesion.

\section{v. CONCLUSION}

The slopes of the $\dot{\varepsilon}-\sigma$ creep curves -0.4 for $\mathrm{SiC}_{\mathrm{f}}-\mathrm{MLAS}$ and 1.4 for $\mathrm{SiC}-\mathrm{SiC}-\mathrm{can}$ correspond to the same damaging mechanism of CMC during the first stage of the creep, by decohesion before matrix microcracking. This can be due to the different values of cohesion, of yield stress, and of creep rate of the different components alone.

\section{ACKNOWLEDGEMENTS}

This work was supported by the GS4C "Comportements thermomécaniques des composites céramique-céramique à fibres" supported by CNES, CNRS, DRET, MRE and Aérospatiale, SEP and SNECMA. This is gratefully acknowledged. Thanks are also specifically due to SEP (F.A.) and Aérospatiale (D.K.) Companies and to CNRS.

\section{REFERENCES}

[1] CHERMANT J.L., ABBE F., KERVADEC D., Proc, of the $5^{\text {th }}$ International Conference on "Creep and Fracture of Engineering Materials and Structures", edited by WILSHIRE B. \& EVANS R.W., The Institute of Materials, 1993, p 371.

[2] CHERMANT J.L., FANTOZZI G., "Microstructure, comportements thermomécaniques et modélisation des composites céramique-céramique à fibres", Rev. Comp. Mat. Avancés $n^{\circ}$ hors série 3 (1993) p 1-298.

[3] ABBE F., Thèse de Doctorat de l'Université de Caen, July 1990.

[4] KERVADEC D., Thèse de Doctorat de l'Université de Caen, December 1992.

[5] CHRISTIN F., NASLAIN R., BERNARD C., Proc. $7^{\text {th }}$ International Conference on"CVD" edited by SEDWICK T.O. \& LYDTIN H., The Electrochemical Society, Princeton, 1979, p 499.

[6] LARNAC G., PERES P., DONZAC J.M., Rev. Comp. Mat. Avancés 3 (1993) 28.

[7] DAVIES C.K.L., STEVENS R.N., Proc. of the $5^{\text {th }}$ International Conference on "Creep and Fracture of Engineering Materials ans Structures", edited by WILSHIRE B. \& EVANS R.W., The Institute of Materials, 1993, p 1.

[8] KERVADEC D., CHERMANT J.L., Proc of the $5^{\text {th }}$ International Conference on "Creep and Fracture of Engineering Materials and Structures", edited by WILSHIRE B. \& EVANS R.W., The Institute of Materials, 1993, p 401. 